\title{
Bullies should be pitied and not feared: the Royal College of Psychiatrists' 16th Annual Debate for Young People
}

Bullying can be fatal. Up to 16 children in the UK kill themselves every year as a result of bullying. Bullying occurs in every school and affects many adults in the workplace. According to some, it is a fact of life in international politics. Whether on the world stage or in the schoolyard, bullying leaves victims feeling lonely and miserable.

Why do some people become bullies? Do bullies have problems of their own that make them behave in the way they do? If we understood them, would we pity the bullies as well as their victims?

Bullying was the subject of the Royal College of Psychiatrists' 16th Annual Debate for Young People. This important educational initiative is organised by the College's External Affairs Department and the Public Education Committee. It is held annually and attracts an audience of almost 300 schoolchildren aged between 15 and 18 years.

This year, the participants were asked to debate the motion: 'This house believes that bullies should be pitied and not feared'. The speakers included two child and adolescent psychiatrists, who drew on their clinical experience of bullying, to both support and oppose the motion. Each side was also supported by a speaker who had conducted research into bullying and its effects.

\section{What makes a bully?}

The proposer of the motion was Helen Cowie, a Professor of Psychology at the University of London. Her research interests include bullying, and she drew on this experience to emphasise the extent of the problem in British schools. The results of one survey (http:// www.mori.com/polls/2000/atl.shtml) showed that onefifth of pupils had been the victims of bullying during the previous term, and a similar proportion felt unsafe in their own neighbourhood.

Cowie explained what factors contribute to an individual becoming a bully, and what might protect against this. Risk factors include:

- a disrupted home life

- harsh parental discipline

- peer delinquency

- living in an area with a high crime rate

- the use of alcohol

Protective factors primarily relate to the school environment, particularly 'violence resilient schools' with supportive teaching staff.

In support of the motion, Cowie argued that understanding the adverse circumstances that create bullies should lead us to pity them. She went on to point out that this same understanding could help us to find ways of tackling bullying, for example by encouraging schools to promote non-violent ways of resolving conflict.

\section{Should bullies be blamed for their actions?}

Steve Kingsbury, a child and adolescent psychiatrist, also in support of the motion, focused on the issue of blame. He claimed that a fear of bullies often leads us to blame them for their actions, and thereby exclude the idea that anything could be done to change their behaviour.

Kingsbury argued that rather than blaming individuals, we should pay more attention to the roles that communities can play in either condoning or combating bullying. According to a study (O'Connell et al, 1999), in half the instances of school bullying an audience gathered to watch, and in a quarter the bully was actually joined by one of the onlookers. The victim was supported in only a quarter of instances. Kingsbury concluded his argument by suggesting that fear and blame of individuals is unhelpful. Instead, we should attempt to understand the role that communities play in the development of bullying, and pity the bully.

\section{Is fear an appropriate reaction?}

Jonathon Bisson, an adult psychiatrist who has conducted research into bullying in the army, led a robust opposition to the motion. Fear, he argued, is an appropriate reaction to a behaviour that is unpleasant, injurious and wrong. The consequences for victims range from anxiety and depression to post-traumatic stress disorder and even suicide.

Bisson went on to explain the physiology of the 'fight or flight' reaction, which he saw as an entirely appropriate response when an individual is being bullied. Not experiencing fear, he argued, would be unhelpful.

The next stage of Bisson's argument was to address the concept of pity. He argued that pity gives the bully positive attention. This might reinforce the bully's behaviour, and even encourage victims to become bullies. However, Bisson did agree with the proposers of the motion in one respect: all schools should have a bullying policy. Prevention, he argued, is better than cure.

\section{Who are the victims of bullying?}

Ann York, a child and adolescent psychiatrist, took a much broader view of bullying to oppose the motion. Illustrating her argument (and pleasing the audience) with a clip from BBC television's Eastenders, she showed how bullies engender terror in their victims. York then 
explained the detrimental effects that bullying has on individuals in the workplace. In one study (http:// www.bullyonline.org, 2002) in which a third of individuals reported experiencing bullying at work, half of these people had considered suicide as a solution to the problem.

York was scathing about the proposers' pleas to pity school bullies. Pitying them, she argued, would only encourage them to grow into adult bullies. They may then end up in positions of national or even international responsibility, making us all potential victims of bullying. The unspoken references to recent international events were not lost on the audience.

Bullies bully in order to gain unwarranted attention and respect. Any pitying of such behaviour, York contested, is highly inappropriate.

\section{Is the argument really so simple?}

The speakers may have been polite in their criticism of each other's arguments, but they provoked some fierce debate and detailed questioning from the audience. Audience members discussed bullying in their own schools, and asked insightful questions about the speakers' own experiences of bullying in school and the workplace.

Audience members were quick to realise that this was not a black and white argument, but one with many grey areas. The speakers acknowledged this, but felt that the presentation of a two-sided view of bullying encouraged by the motion facilitated a deeper exploration of some of the issues in a complex subject.

\section{The verdict}

There may have been shades of grey in the debate, but at its end the audience was asked to vote for whichever team had convinced them of their side of the argument. Before the debate, the majority of the audience had voted for the motion, but the opposition swung the vote to produce a final vote against.

Regardless of the outcome, both the proposers and opposers of the motion should be congratulated on explaining a complex subject so clearly. Their ability to engage the audience was demonstrated by the liveliest question and answer session for some years.

We could no doubt argue that there is a fine line between robust debate and verbal bullying. However, the young audience opted for debate and reasoned argument on a complex issue of human behaviour. Perhaps our world leaders should take a leaf out of their book.

\section{Acknowledgements}

We thank Professor Helen Cowie, Dr Steve Kingsbury, Dr Jonathon Bisson and Dr Ann York for such an entertaining and informative debate.

*Jim Bolton Consultant Liaison Psychiatrist and Honorary Senior Lecturer, St Helier Hospital, Wrythe Lane, Carshalton, Surrey SM51AA

Email: jgbolton@sghms.ac.uk, Ros Ramsay Consultant Adult Psychiatrist, South London \& Maudsley NHS Trust, Deborah Hart Head of External Affairs, The Royal College of Psychiatrists 